\title{
Intra-axonal recording from large sensory myelinated axons: Demonstration of impaired membrane conductances in early experimental diabetes
}

\author{
Jasna Kriz, Ante L. Padjen \\ Department of Pharmacology and Therapeutics, McGill University, Montréal, Canada
}

\begin{abstract}
Aim/hypothesis. Diabetic neuropathy is accompanied by a range of positive (paresthaesia, dysesthaesia, pain) and negative (hypesthaesia, anesthaesia) neurological symptoms suggesting widespread alterations in axonal excitability. The nature and the mechanisms underlying these alterations in axonal excitability are not well understood. The aim of this study was to examine the extent of changes in membrane properties of an identified neuronal structure - the large myelinated sensory axons in early experimental diabetes in rats. Methods. Intra-axonal microelectrode recordings from large sensory myelinated axons from the isolated sural nerve in short-term streptozotocin-induced diabetic rats were used to study membrane properties using standard current-clamp technique.

Results. In addition to decreased conduction velocity we found several differences in physiological proper-
\end{abstract}

ties of sensory axons from diabetic rats: decreased resting membrane potential, decreased single action potential amplitude associated with slower rate of rise and decrease in inward rectification associated with slight alteration in outwardly rectifying conductances indicating impaired potassium conductances.

Conclusion/Interpretation. These results extend previous indirect evidence that potassium and sodium ionic conductances, most notably the inward rectifier (IR, $\mathrm{I}_{\mathrm{h}}$ ), are altered in large sensory axons of diabetic rats. The depression of IR could underly clinical neurological findings in diabetic patients. [Diabetologia (2003) 46:213-221]

Keywords Diabetic neuropathy, streptozotocin, rats, sensory myelinated axons, intra-axonal recording, action potential, inward rectification.
The peripheral neuropathy associated with diabetes is one of the most common polyneuropathies, and at least $50 \%$ of diabetic patients will develop a form of

Received: 6 September 2002 / Revised: 18 October 2002

Published online: 18 February 2003

(C) Springer-Verlag 2003

Corresponding author: Dr. Ante L. Padjen, Department of Pharmacology and Therapeutics, McGill University, 3655 Sir William Osler Promenade (ex-Drummond), Montréal, QC H3G 1 Y6 Canada

E-mail: alp@pharma.mcgill.ca

Abbreviations: AP, action potential; AP/2, AP half amplitude level; CV, conduction velocity; DAP, depolarizing afterpotential; DN, diabetic neuropathy; Ih, slow inward rectifier; RMP, resting membrane potential; Rp, peak resistance; Rss, steady state resistance; STZ, streptozotocin. diabetic neuropathy within 25 years after diagnosis [1]. The pathogenesis of diabetic neuropathies and consequently their treatment remain elusive, in spite of a number of hypotheses advanced in the past decades. These hypotheses deal with several major areas, such as metabolic, ischaemia and oxidative stress, non-specific glycosylation, and disturbances in trophic factors $[1,2,3,4]$. The histopathological findings of advanced diabetic neuropathy (DN) are characterized by axonal degeneration, demyelination and atrophy that are associated with highly diverse disturbances of peripheral nerve function $[2,5,6]$. Different positive and negative neurological signs associated with DN suggest modification in axonal membrane excitability. Indeed, one of the earliest detectable physical signs of early $\mathrm{DN}$ is a decrease in conduction velocity as signs 
of changes in excitability of peripheral nerves [7]. At the moment, little is known about the possible mechanisms involved in pathological changes in nerve function, however modification of axonal membrane conductances clearly is one of the factors involved [7, 7, 9].

Myelinated axons express a rich repertoire of ion channels selectively distributed in cellular compartments and serving the physiological role of myelinated axons to conduct nerve impulses [10, 11, 12]. Fast sodium channels located almost exclusively on nodal membrane are modulated by fast and slow outwardly rectifying potassium conductances located in the internodal membrane $[11,13,15]$. In addition, inward rectification induced by membrane hyperpolarization has also been shown in axons of the mammalian $[16,17$, $18,19]$ and amphibian [20] peripheral nervous system.

In mammalian myelinated axons the inward rectifier is activated relatively slowly by membrane hyperpolarization, it is permeable to both $\mathrm{Na}^{+}$and $\mathrm{K}^{+}$ions, blocked by extracellular application of $\mathrm{Cs}^{+}[11,15$, 16] and, unlike $\mathrm{I}_{\mathrm{KIR}}$, also blocked by a specific antagonists ZD 7288 of $\mathrm{I}_{\mathrm{h}}$ found in neuronal cell bodies [21, 22].

Axonal excitability is increased during the activation of this current, as a result of the depolarization that occurs as $\mathrm{Na}^{+}$and $\mathrm{K}^{+}$enter the axons. Therefore it is suggested that this conductance may maintain membrane potential during and after the high frequency firing that otherwise might result in excessive membrane hyperpolarization.

Previous extracellular studies on whole nerves showed that inward rectification is decreased in peripheral nerves exposed to hyperglycaemic hypoxia, a common complication of diabetes mellitus [23, 24, 25]. Recent findings by indirect electrophysiological methods indicate that inward rectification could be altered in human diabetic neuropathy [8] as well as in experimental diabetes [9] - (for a review see [7]).

In this study we examine rectifying and steady state properties of large myelinated axons from isolated sural nerve fibres in control and streptozotocin (STZ)-diabetic rats by intra-axonal recording and standard currentclamp technique. We report here that inward rectification and other ion conductances are impaired in large myelinated sensory axons of diabetic rats [26, 27].

\section{Material and Methods}

Experimental groups and diabetes induction. Experiments were carried out on STZ-treated Sprague Dawley male rats and age-matched control rats. Diabetes was induced in 3- to 4week-old rats (weight 90-100 g) by three injections of STZ (45 mg/kg i.p. on three consecutive days). The rats were weighed regularly and their blood glucose concentration was measured (Medisense, Abbott Labs) in samples drawn from the tail vein. After 12 week of diabetes animals were hyper- glycaemic, $24.2 \pm 0.98 \mathrm{mmol} / \mathrm{l}$ compared with $8.3 \pm 0.66 \mathrm{mmol} / \mathrm{l}$ (means \pm SE, $n=10$ ) with an approximate weight loss of $30 \%$ in diabetic animals.

The rats were killed by an overdose of anaesthetic (halothane). Sural nerves were quickly dissected out, pinned to the bottom of the wax-coated chamber with the insect needles and continually perfused with mammalian Ringer, containing in $\mathrm{mmol} / \mathrm{l}: 127 \mathrm{NaCl}, 1.9 \mathrm{KCl}, 2.4 \mathrm{CaCl}_{2}, 1.2 \mathrm{KH}_{2} \mathrm{PO}_{4}, 1.3$ $\mathrm{MgSO}_{4}, 26 \mathrm{NaHCO}_{3}$ and 10 glucose, saturated with $5 \%$ carbon dioxide and $95 \%$ oxygen $\left(\mathrm{pH}=7.4\right.$, temperature $\left.22-25^{\circ} \mathrm{C}\right)$. All procedures were approved and carried out according to the McGill University Animal Care Committee.

Electrophysiology. Identification of axons and sampling procedure. Intracellular recordings were obtained from the isolated sural nerve. In keeping with our previous experiments on amphibian and mammalian nerves, [20,28, 29] and the conduction velocity ( $>25 \mathrm{~m} / \mathrm{s}$ at room temperature, as assessed by the latency between stimulus artefact and the rising phase of the action potential) all of the recorded axons belonged to a population of large myelinated axons. It is technically unlikely to obtain the stable intra-axonal recording from the axons that are less than 7 to $8 \mu \mathrm{m}$ in diameter. In all our experiments at least two stable recordings were obtained from different axons from each sural nerve. Action potentials were evoked by brief $0.02 \mathrm{~ms}$ current pulses applied to the proximal trunk of the sciatic nerve via bipolar platinum electrodes at frequencies of 0.5 to $1.0 \mathrm{~Hz}$. Axons were considered suitable for experiments if the resting membrane potential after stabilization was more negative than $-65 \mathrm{mV}$ (in control animals). Unlike amphibian, the depolarizing afterpotentials (DAPs) are observed only in $15 \%$ of sampled axons in mammalian axons $[32,33,34,35$, $36]$ and therefore they were not studied. The microelectrode technique used in this study allows recording from undissected axons; it is likely that that such recordings reflect the excitability in vivo well $[20,30]$.

Microelectrode recording technique. Glass microelectrodes were prepared with a Brown-Flaming puller (Sutter Instruments, San Francisco, Calif., USA), filled with $\mathrm{KCl}$ (3 M) and had D.C. resistance 60 to $80 \mathrm{M} \Omega$.

Microelectrodes were selected for their low noise and ability to pass less than or equal to $2 \mathrm{nA}$ without rectification and were connected to Axoclamp 2B (Axon Instruments, Foster City, Calif., USA). An active bridge circuit allowed simultaneous current injection and recording through the same electrode ("current-clamp" technique). After capacity compensation the rise time (5-95\%) of $50 \mathrm{mV}$ voltage calibration pulse was 20 to $50 \mu$ s. This bandwidth allowed for appropriate bridge balance. Occasionally, bridge balance was checked independently by ensuring that the action potential overshoot remained constant [31]. After differential amplification (Axoclamp 2B, Axon Instruments) at $20 \mathrm{kHz}$ following the low pass 8-pole Bessel filter set at $10 \mathrm{kHz}$, and a 16 bit A/D converter (ITC 16 Instrutech) with appropriate software (TIDA for Windows) records were stored on a computer for further analysis.

Differentiation of signals was done by computation of digital recording and data expressed as $\mathrm{dV} / \mathrm{dt}$.

Data analysis. Whenever appropriate, results were expressed as means \pm standard error (SE). Statistical significance was assessed using one-way ANOVA followed by a Tukey HSD test. A $p$ value of less than or equal to 0.05 was considered statistically significant. 

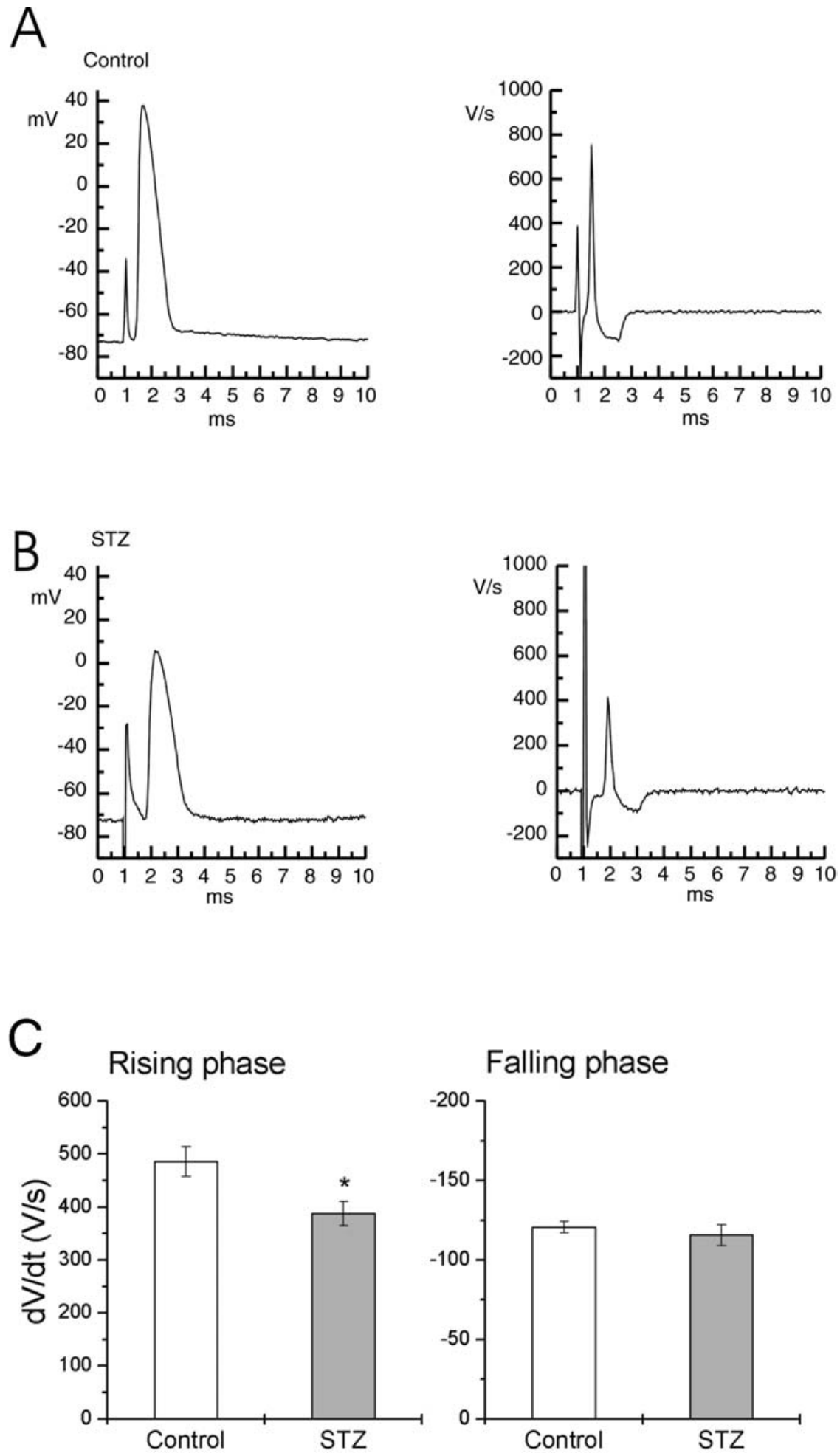

Fig. 1A-C. Smaller action potential in sensory axon of diabetic rats. Intra-axonal microelectrode recording from sural nerves. Action potentials from control (A) and STZ-treated rats (B) sural nerves with corresponding first-order differential traces $(\mathrm{dV} / \mathrm{dt})$. (C) Average maximum and minimum $\mathrm{dV} / \mathrm{dt}$ values recorded from control and STZ diabetic rats. Each column represents means \pm SE (control $n=22$, diabetic $n=25$ ); *significantly different from control, $p \leq 0.05$

\section{Results}

Resting membrane potential. Stable intra-axonal recordings described in this study were obtained from more than 50 randomly-impaled axons from isolated sural nerves of control rats and diabetic rats. Intracellular placement of the electrode was indicated by a sharp drop in the recorded potential (usually -65 to -70 in control axons) and the appearance of the brief 
Table 1. Resting and action potentials recorded in large myelinated in axons from control and STZ rats

\begin{tabular}{lllll}
\hline & RMP $(\mathrm{mV})$ & $\mathrm{AP}(\mathrm{mV})$ & $\mathrm{AP} / 2(\mathrm{~ms})$ & $\mathrm{CV}(\mathrm{m} / \mathrm{s})$ \\
\hline Control & $-73.5 \pm 0.67$ & $90.74 \pm 2.6$ & $0.77 \pm 0.09$ & $27.63 \pm 1.68$ \\
STZ & $\mathbf{- 7 0 . 8} \pm \mathbf{0 . 9 2} *$ & $\mathbf{8 3 . 6} \pm \mathbf{3 . 4} *$ & $0.79 \pm 0.03$ & $\mathbf{1 7 . 8 6} \pm \mathbf{0 . 7 7} *$ \\
\hline
\end{tabular}

RMP $=$ Resting membrane potential (Control, $n=32 ;$ STZ, $n=33)$, AP $=$ action potential amplitude measured at resting membrane potential; AP/2 = half amplitude AP duration (Control, $n=27$; STZ, $n=18), \mathrm{CV}=$ conduction velocity $(\mathrm{CV})$. Values represent means \pm SE. Data marked in bold* type are statistically significant from controls, $p \leq 0.05$. Intra-axonal recordings at $22-23^{\circ} \mathrm{C}$

action potential in response to stimulating pulse. Within 10 to 15 min the membrane potential stabilized. The average resting membrane potential was less negative in isolated axons from the diabetic rats (control, $-73.5 \pm 0.57 \mathrm{mV}$ vs. $-70.8 \pm 0.92 \mathrm{mV}$ in $\mathrm{d}$, means \pm SE, $n=32$ ) (Table 1$)$.

Characteristics of action potentials. As measured at half amplitude level (AP/2, Table 1) at resting membrane potential there was no difference in the action potential duration between the axons from control rats and those from diabetic rats. However, the action potentials recorded from myelinated axons of diabetic rats were smaller (Table 1; Fig. 1). This decrease in amplitude of action potential in axons of diabetic animals was associated with a decrease in the rate of the rising phase (depolarization) of action potentials (measured by differentiation and expressed as $\mathrm{dV} / \mathrm{dt}$; $486.04 \pm 28$ vs. $388 \pm 23 \mathrm{~V} / \mathrm{s} ; n=25$ and 23 , respectively for control and STZ-treated rats, respectively; Fig. 1). There was no difference in the rate of the falling phase (repolarization) of action potential (Fig. 1B).

Action potentials in myelinated axons are often followed by a depolarizing after-potential (DAP; Fig. 1A). The difference in DAP between control rats and diabetic rats as observed in Fig. $1 \mathrm{~A}$ is not significant.

When comparing the membrane potential and the rate of the rise of AP $(\mathrm{dV} / \mathrm{dt})$ there was a decrease in the correlation coefficient in diabetic rats compared with control rats, suggesting that the slower rate of rise in diabetic animals was not due to membrane depolarization but rather due to decreased voltage sensitivity of $\mathrm{Na}^{+}$channel (Fig. 2).

Conduction velocity. Conduction velocity was measured during stimulation of the distal trunk of the isolated sural nerve. It was calculated as the ratio between the latency of the stimulus artefact and the rising phase of an action potential and the distance between the stimulating and recording electrode. As expected, the average conduction velocity recorded from single myelinated axons from diabetic rats was re-
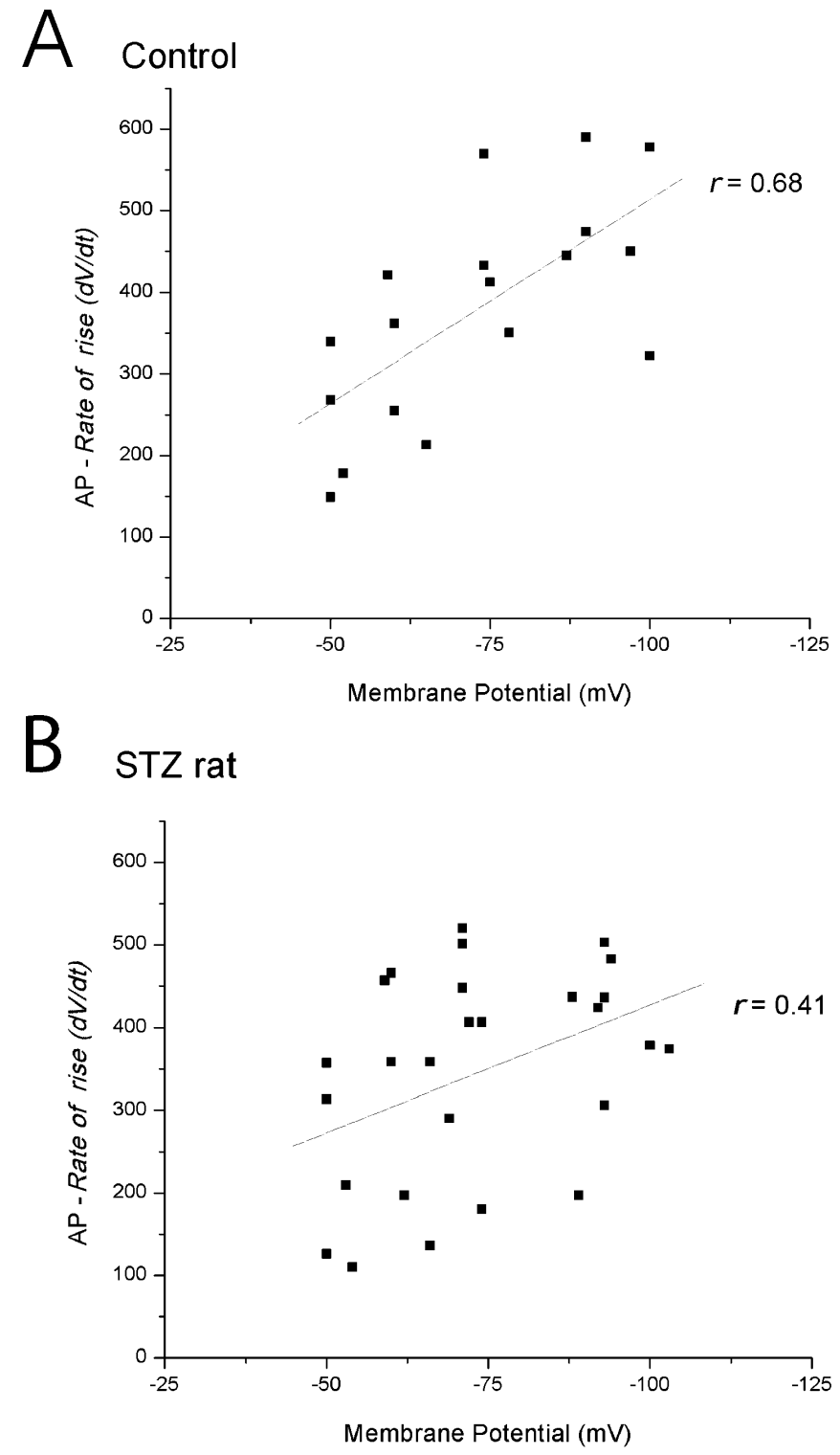

Fig. 2A, B. Correlation between $\mathrm{d} V / \mathrm{d} t$ of rising phase of an action potential and membrane potential. Note the difference between the correlation coefficients indicating decreased voltage sensitivity of $\mathrm{Na}^{+}$channels in diabetic animals (STZ rats; B) vs. control (A)

duced $(17.9 \pm 0.8$ vs. $27.6 \pm 1.7$ for control rats, measured at room temperature, $23^{\circ} \mathrm{C}$; Table 1 ).

Rectifying properties of axonal membrane. Intracellular injections of $200 \mathrm{~ms}$ depolarizing and hyperpolarizing current steps were used to examine the membrane properties of myelinated axons. The membrane voltage responses to current steps were characterized by several phases. In response to depolarizing steps a fast rising phase was followed by a slower rising response representing two outwardly rectifying conductances. As noted previously in mammalian and amphibian myelinated axons the action potential generation shows strong accommodation to depolarizing 

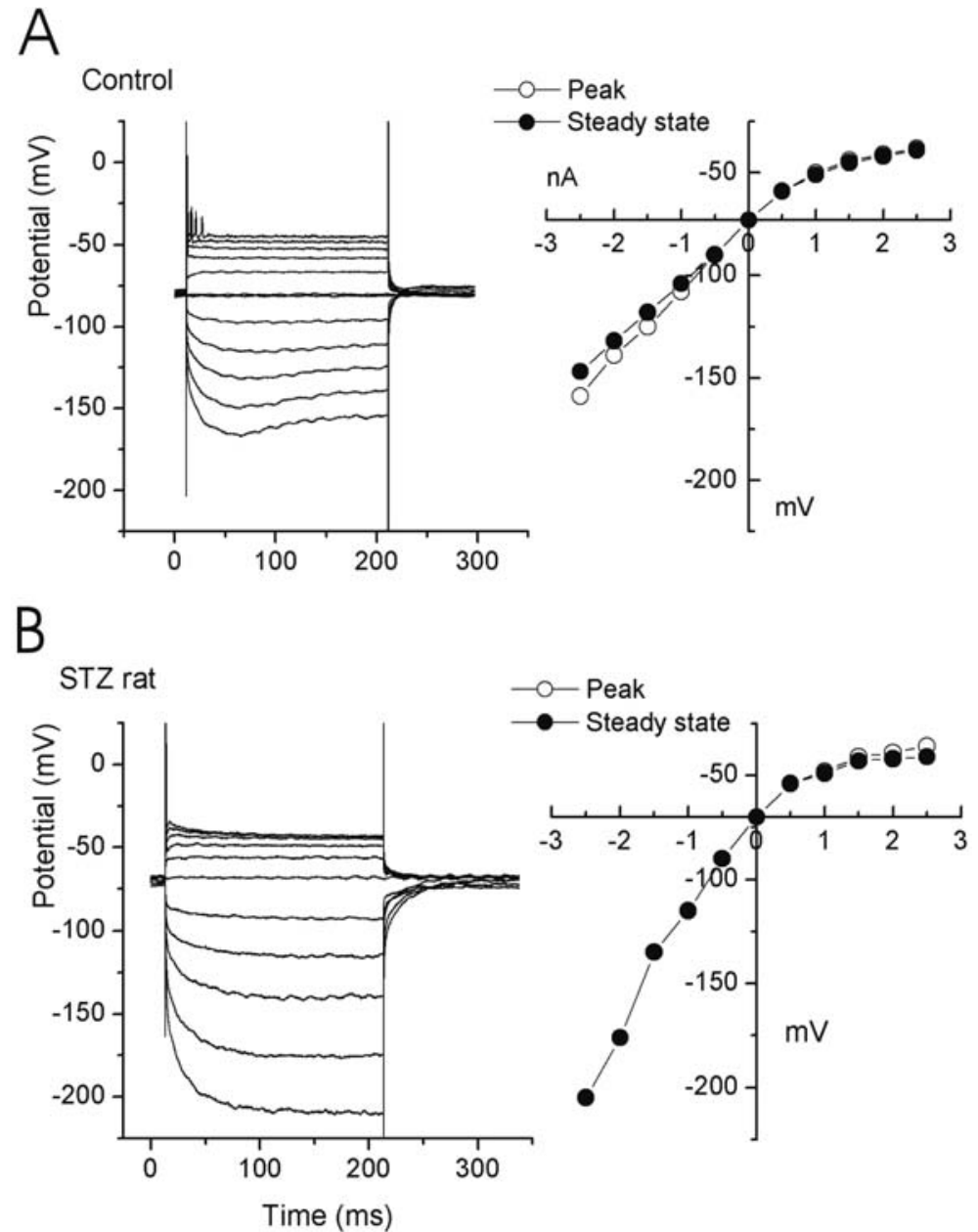

Fig. 3A, B. Examples of characteristic voltage membrane responses to current steps (200 ms duration, $0.5 \mathrm{nA}$ steps, not shown) and corresponding voltage/current plots recorded from single axon. (A) from control rat; (B) from diabetic rat. Note lack of sag in hyperpolarizing voltage responses in STZ-treated rats

stimuli resulting in cessation of spiking (Fig. 3A). The difference in accommodation of action potential generation among experimental groups was not significant.

In response to the hyperpolarizing pulses, membrane voltage responses of control axons showed characteristic upward "sag". (Fig. 3A). This sag was typically observed between 100 to $150 \mathrm{~ms}$ after the initiation of the current pulse and at membrane potentials 10 to $40 \mathrm{mV}$ below RMP. It is generally accepted that this phenomenon reflects the activation of a slow inward current $\left(\mathrm{I}_{\mathrm{h}}\right)$ in axons $[10,11]$. Compared to the control rats, the axons of diabetic animals showed reduced upward sag, suggesting a decrease in inward rectification in these animals (Fig. 3, A vs B).

The voltage-current (V-I) relationship was constructed by plotting membrane potential at the peak of the voltage displacement and at the steady state near the end of the current step. The V-I relationship was strongly non-linear, reflecting the activation of more than one voltage-dependent conductance (Fig. 3A). The V-I plots from axons of diabetic animals were characterized by a decrease of time-dependent inward rectification (Fig. 3B).

The results were quantified by calculating the input resistance at different regions of the V-I relationships. In response to hyperpolarizing current pulses, at membrane potentials below $-100 \mathrm{mV}$, two linear V-I relationships were used to calculate the input resistance: one obtained at the peak of responses $\left(\mathrm{hR}_{\mathrm{p}}\right.$, peak resistance) and the other at the steady state $\left(h R_{\mathrm{ss}}\right.$, for steady state resistance). Comparison of input resistances in sensory axons of diabetic animals in response to hyperpolarization showed an increase in $\mathrm{hR}_{\mathrm{ss}}$ values, i.e. a decrease in inward rectification (35.3 $\pm 2.6 \mathrm{M} \Omega$, for control, vs. 45.0 $\pm 5.0 \mathrm{M} \Omega$, means $\pm \mathrm{SE}$, control $n=17$, STZ, $n=21$; Fig. $4 \mathrm{~A}$ ).

Similarly, the input resistance to depolarizing stimuli was measured at two points: $\mathrm{dR}_{\mathrm{p}}$, at 15 to $20 \mathrm{~ms}$ after pulse onset, and the steady state, $\mathrm{dR}_{\mathrm{ss}}, 175 \mathrm{~ms}$ later (Fig. 4B). In response to depolarization myelinated axons of diabetic animals showed a slight increase in $\mathrm{dR}_{\mathrm{p}}$ values $(15.93 \pm 0.79 \mathrm{M} \Omega$, control, compared to $19.8 \pm 0.96 \mathrm{M} \Omega$, for diabetic axons, control $n=17$, 

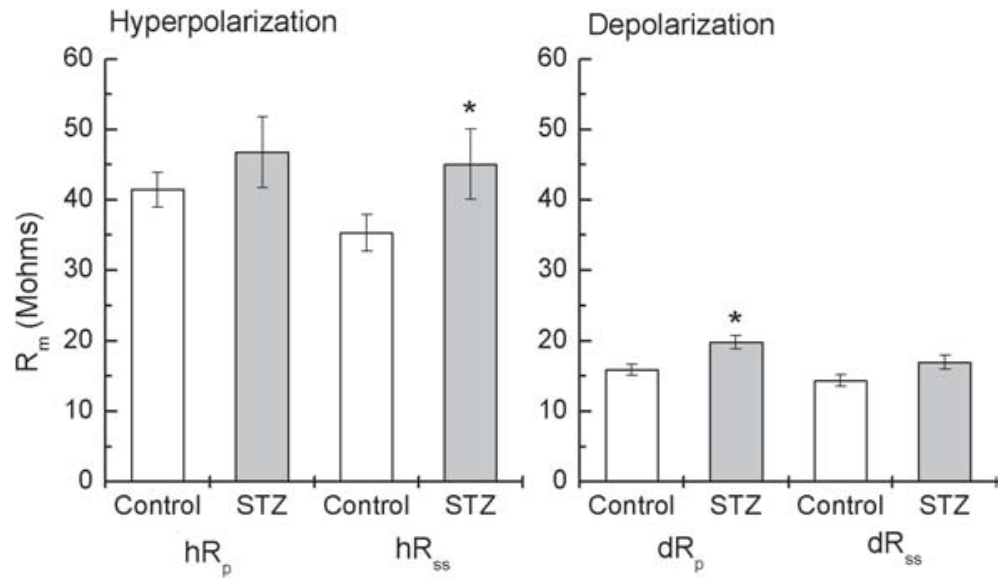

Fig. 4. The average peak and steady state input resistance recorded during evoked hyperpolarization $\left(\mathrm{hR}_{\mathrm{p}}\right.$ and $\mathrm{hR}$ ss $)$ and depolarization $\left(\mathrm{dR}_{\mathrm{p}}\right.$ and $\left.\mathrm{dR}_{\mathrm{ss}}\right)$ in control and in the axons from STZ-diabetic rats. Each column represents means \pm SE, (control, $n=17, \mathrm{STZ} n=21)$, significantly different from control, $p \leq 0.05$

STZ=21) suggesting decreased activity of the fast outwardly-rectifying conductance (Fig. 4B).

\section{Discussion}

In this study using intra-axonal microelectrode recording we have shown decreased conduction velocity and altered membrane properties $\left(\mathrm{Na}, \mathrm{K}\right.$ and $\mathrm{I}_{\mathrm{h}}$ conductances) of large myelinated sensory axons in shortterm STZ-induced diabetic rats. Unlike previous studies that used either recording from single nodes of Ranvier or indirect measurements of axonal properties intra-axonal recording provides information about the single undissected axon which is especially relevant for understanding the complex functions of myelinated axon [10,11], as discussed in the following sections.

Reduction of $C V$ in experimental diabetic neuropathy. A decrease in nerve conduction velocity is an early feature of human diabetic neuropathy (cf. $[3,37]$ ) and of experimental animal models (cf. [5]). Our results confirm that this abnormality is in large sensory myelinated axons.

The mechanisms underlying the slowdown of conduction velocity in early diabetes are not completely clear although there are several possibilities. The axon calibre is the most sensitive parameter affecting conduction velocity [38]. In chronic diabetes nerve conduction slowdown has been associated with neuroanatomical abnormalities [6, 39]. This is unlikely to be relevant for early diabetes, as recently shown in the diabetic rat [40].

We have shown a disparity between the unchanged axon calibre and decreased conduction velocity in peripheral nerves of transgenic mice with neurofilament $\mathrm{H}$ knock-out [35]. These findings point out that change in axonal membrane properties, such as reported in this study, are more likely to affect conduction velocity.

$N a \& K$ conductances are impaired in early animal diabetes. Early voltage clamp studies on nodal membrane indicated impaired permeability of $\mathrm{Na}$ channels [41]. Several possible explanations were proposed for this finding, such as (i) depolarization, (ii) defective ion channel function and (iii) a change in ion channel density and distribution.

(i) Depolarization of axonal membrane could result from $\mathrm{Na}, \mathrm{K}$ pump blockade in diabetic animals (cf. $[27,42])$ and/or suppression of inward rectifier, as reported in this study.

As expected, the intra-axonal recordings showed a decrease in amplitude of AP in large myelinated axons associated with a decrease in $\mathrm{dV} / \mathrm{dt}$ of AP rising phase. However, this decrease is not only due to membrane depolarization but rather consistent with altered kinetics of sodium channel activation, as shown by the difference in correlation between the membrane potential and the rate of rise. The membrane depolarization of peripheral nerves in diabetic neuropathy has recently been discounted on the basis of the indirect but sensitive threshold tracking technique [43].

(ii) $\mathrm{Na}$ channel (and $\mathrm{K}$ or $\mathrm{I}_{\mathrm{h}}$ channel) function can be affected by metabolic changes in diabetes through changed activity of intracellular second messengers and protein kinases. Recent studies in this laboratory indicate that the phosphorylation state of $\mathrm{Na}$ channels in peripheral nerves from diabetic animals could be affected, possibly because of changed activity of phophatases [44]. In addition to this postranslational changes of $\mathrm{Na}$ channels function it is possible that the diabetic state affects ion channel transcription. Thus studies in this laboratory show upregulation of a slow $\mathrm{Na}$ channel in peripheral nerves [45] and other data 
showed increased expression of the beta unit of the $\mathrm{Na}$ channel [46].

(iii) The molecular organization of the nodal region is not altered in BB-Wistar rat model of diabetes [47].

The responses of axonal membrane during depolarization associated with corresponding increase in input resistance, clearly suggest that fast $\mathrm{K}^{+}$outwardly rectifying conductances are diminished in early experimental diabetes in agreement with previous studies by indirect techniques $[7,25]$.

An impairment of $K$ conductances in diabetes is observed in other excitable tissues, such as the heart suggesting a generalized $\mathrm{K}$ conductance defect. It has been reported that the fast $\mathrm{K}^{+}$channel activity is reduced by $50 \%$ at cytoplasmic $\mathrm{pH}$ of 6.8 as a result of enhanced anaerobic glycolysis [24, 48]. Decreased K channels could also explain our finding of membrane depolarization.

Inward rectification is reduced in early diabetic neuropathy. The most evident defect in diabetic sensory axons in our study was a attenuation of time dependent slow inward rectification associated with $\mathrm{I}_{\mathrm{h}}$. Clinical studies using the threshold electrotonus technique have provided evidence that $\mathrm{I}_{\mathrm{h}}$ also occurs in human axons in situ [49], and that its effects on excitability are more pronounced in sensory than motor axons [50]. Recent data from peripheral nerves in human diabetic neuropathy indicate that axonal inward rectification might be diminished [8]. The abnormalities in diabetic patients were positively correlated with the age of patients and having neuropathy [8]. Using a similar technique on peripheral nerves in STZ-induced diabetic rats, another study also recorded a decrease in inward rectification that was reversed by an aldose reductase inhibitor treatment [9].

Functional implications. It is well recognized that experimental STZ diabetic rats develop neurological defects similar to those in human diabetic neuropathy: chronic pain as well as other signs of peripheral neuropathies, such as hyperalgesia to mechanical and chemical stimuli ([51, 52, 53]) and mechanical allodynia [54]. Therefore it is reasonable to expect that the mechanism of the defects is similar to human pathology. This study indicates that the large axons are also affected in early diabetes, in agreement with the clinical findings of impaired perception of vibration [5], that is commonly used to assess the function of large afferent $\mathrm{A} \beta$ fibers $[55,56]$.

Activation of $\mathrm{I}_{\mathrm{h}}$ by hyperpolarization leads to depolarization that brings the membrane potential back towards the resting potential $[11,15,16,22]$. Although the role of inward rectification in axons is not yet fully understood its activation prevents excessive hyperpolarization and possible conduction failure that might occur during high frequency firing $[16,17]$. However, the effects of impaired $I_{h}$ in diabetic neuropathy is minimized by the concomitant reduction in Na pumping (see above) and membrane depolarization.

The mechanism of the blockade of $I_{h}$ in diabetic neuropathy is unknown. Besides its voltage-dependence, $I_{h}$ is regulated by intracellular cyclic AMP concentration $[22,57,58,59]$ that is known to be decreased in diabetic nerves $[60,61]$.

In summary, our data show changes in nerve fibre conduction and excitability in early experimental diabetes that could provide the basis for some clinical symptoms related to diabetic neuropathy and possible targets for therapeutic intervention.

Acknowledgements. These studies were supported in part by grants from MRC, CDA and ALS. We thank Prof. K. Krnjevic for comments on an earlier version of the manuscript.

\section{References}

1. Dyck PJ, Thomas PK (1999) Diabetic neuropathy. WB Saunders, Philadelphia

2. Vinik AI, Park TS, Stansberry KB, Pittenger GL (2000) Diabetic neuropathies. Diabetologia 43:957-973

3. Sima AAF, Sugimoto K (1999) Experimental diabetic neuropathy: an update. Diabetologia 42:773-788

4. Zochodne DW (1999) Diabetic neuropathies: features and mechanisms. Brain Pathol 9:369-391

5. Thomas PK, Tomlinson DR (1992) Diabetic and hypoglycemic neuropathy. In: Dyck PJ, Thomas PK (eds) Peripheral neuropathy. WB Saunders, Philadelphia, pp 1219-1250

6. Sugimoto K, Murakawa Y, Sima AA (2000) Diabetic neuropathy - a continuing enigma. Diabetes Metab Res Rev 16:408-433

7. Quasthoff S (1998) The role of axonal ion conductances in diabetic neuropathy: a review. Muscle Nerve 21:12461255

8. Horn S, Quasthoff S, Grafe P, Bostock H, Renner R, Schrank B (1996) Abnormal axonal inward rectification in diabetic neuropathy. Muscle Nerve 19:1268-1275

9. Yang Q, Kaji R, Takagi T, et al. (2001) Abnormal axonal inward rectifier in streptozocin-induced experimental diabetic neuropathy. Brain 124:1149-1155

10. Ritchie JM (1995) Physiology of axons. In: Waxman SG, Kocsis JD, Stys PK (eds) The axon. Structure, function and pathophysiology, pp 68-96

11. Waxman SG (1995) Voltage-gated ion channels in axons: Localization, function, and development. In: Waxman SG, Kocsis JD, Stys PK (eds) The axon. Structure, function and pathophysiology, pp 218-243

12. Rasband MN, Shrager P (2000) Ion channel sequestration in central nervous system axons. J Physiol (Lond) 525: 63-73

13. David G, Barrett JN, Barrett EF (1993) Activation of internodal potassium conductance in rat myelinated axons. $\mathrm{J}$ Physiol (Lond) 472:177-202

14. Chiu SY, Ritchie JM (1984) On the physiological role of internodal potassium channels and the security of conduction in myelinated nerve fibres. Proc R Soc Lond [Biol] 220:415-422

15. Waxman SG, Ritchie JM (1993) Molecular dissection of the myelinated axon. Ann Neurol 33:121-136

16. Baker M, Bostock H, Grafe P, Martius P (1987) Function and distribution of three types of rectifying channel in rat 
spinal root myelinated axons. J Physiol (Lond) 383:4567

17. Eng DL, Gordon TR, Kocsis JD, Waxman SG (1990) Current-clamp analysis of a time-dependent rectification in rat optic nerve. J Physiol (Lond) 421:185-202

18. Birch BD, Kocsis JD, Di Gregorio F, Bhisitkul RB, Waxman SG (1991) A voltage- and time-dependent rectification in rat dorsal spinal root axons. J Neurophysiol 66:719-727

19. Takigawa T, Alzheimer C, Quasthoff S, Grafe P (1998) A special blocker reveals the presence and function of the hyperpolarization-activated cation current $\mathrm{IH}$ in peripheral mammalian nerve fibres. Neuroscience 82:631-634

20. Poulter MO, Hashiguchi T, Padjen AL (1993) An examination of frog myelinated axons using intracellular microelectrode recording: the role of the voltage dependent and leak conductances on the steady state electrical properties. J Neurophysiol 70:2301-2312

21. Luthi A, McCormick DA (1998) H-current: properties of a neuronal and network pacemaker. Neuron 21:9-12

22. Pape HC (1996) Queer current and pacemaker: the hyperpolarization-activated cation current in neurons. Annu Rev Physiol 58:299-327

23. Schneider U, Quasthoff S, Mitrovic N, Grafe P (1993) Hyperglycaemic hypoxia alters after-potential and fast $\mathrm{K}+$ conductance of rat axons by cytoplasmic acidification. J Physiol (Lond) 465:679-697

24. Grafe P, Bostock H, Schneider U (1994) The effects of hyperglycaemic hypoxia on rectification in rat dorsal root axons. J Physiol (Lond) 480:297-307

25. Grafe P(1996) Anin vitro model of diabetic neuropathy: electrophysiological studies. In: Bostock H, Kirkwood PA, Pullen AH (eds) The neurobiology of disease. Cambridge University Press, Cambridge, pp 61-68

26. Kriz J, Zhu Q, Mayer J, Simonic A, Julien JP, Padjen AL (1999) Impaired ionic conductances in myelinated axons of peripheral nerves from transgenic mice with different neurofilament expression. Proc IBRO Meet, Jerusalem

27. Kriz J, Hashiguchi T, Tanaka A, Mrsic J, Maysinger D, Padjen AL (1997) Defects in membrane excitability and electrogenic $\mathrm{Na}, \mathrm{K}$ pumping in diabetic neuropathy. Can $\mathrm{J}$ Diabetes Care 21:S16

28. Hashiguchi T, Padjen AL (1983) Membrane properties of primary afferent axons: a study by intracellular recording. Soc Neurosci Abstr 9:511

29. Kriz J, Mayer J, Julien JP, Padjen AL (2000) Altered ionic conductances in axons of trangenic mouse expressing the human neurofilament heavy gene: a mouse model of amyotrophic lateral sclerosis. Exp Neurol 163:414-421

30. Poulter MO, Padjen AL (1995) Different voltage dependent potassium conductances regulate action potential repolarization and excitability in frog myelinated axon. Neuroscience 68:497-504

31. Frank K, Fuortes MGF (1956) Stimulation of spinal motoneurons with intracellular electrodes. J Physiol (Lond) 134:451-470

32. Blight AR, Someya S (1985) Depolarizing afterpotentials in myelinated axons of mammalian spinal cord. Neuroscience 15:1-12

33. Bowe CM, Kocsis JD, Waxman SG (1987) The association of the supernormal period and the depolarizing afterpotential in myelinated frog and rat sciatic nerve. Neuroscience 21:585-593

34. David G, Modney B, Scappaticci KA, Barrett JN, Barrett EF (1995) Electrical and morphological factors influencing the depolarizing after-potential in rat and lizard myelinated axons. J Physiol (Lond) 489:141-157
35. Kriz J, Zhu Q, Julien JP, Padjen AL (2000) Electrophysiological properties of axons in mice lacking neurofilament subunit genes: disparity between conduction velocity and axon diameterin absence of NF-H. Brain Res 885:32-44

36. Poulter MO, Hashiguchi T, Padjen AL (1989) Dendrotoxin blocks accommodation in frog myelinated axons. J Neurophysiol 62:174-184

37. Daube JR (1999) Electrophysiologic testing in diabetic neuropathy. In: Dyck PJ, Thomas PK (eds) Diabetic neuropathy. WB Saunders, Philadelphia, pp 222-238

38. Brill MH, Waxman SG, Moore JW, Joyner RW (1977) Conduction velocity and spike configuration in myelinated fibres: computed dependence on internode distance. J Neurol Neurosurg Psychiatry 40:769-774

39. Giannini C, Dyck PJ (1999) Pathologic alterations in human diabetic polyneuropathy. In: Dyck PJ, Thomas PK (eds) Diabetic neuropathy. W.B. Saunders, Philadelphia, pp 279-296

40. Walker D, Carrington A, Cannan SA, et al. (1999) Structural abnormalities do not explain the early functional abnormalities in the peripheral nerves of the streptozotocin diabetic rat. J Anat 195:419-427

41. Brismar T (1993) Abnormal Na-currents in diabetic rat nerve nodal membrane. Diabet Med 10 [Suppl 2]:110S$112 \mathrm{~S}$

42. Hashiguchi T, Tanaka A, Cristall J, Maysinger D, Padjen AL (1996) Electrogenic Na,K pumping in diabetic neuropathy. Abstr Soc Neurosci 22:2135

43. Strupp M, Bostock H, Weigl P, Piwernetz K, Renner R, Grafe $P$ (1990) Is resistance to ischaemia of motor axons in diabetic subjects due to membrane depolarization? J Neurol Sci 99:271-280

44. Dupont M, Tam J, Maysinger D, Padjen AL (2000) Electrophysiological and biochemical evidence for marked defects in PKC and MAPK signaling pathways in peripheral nerves in experimental diabetes. Soc Neuroscience Abstr 26:600

45. Rados M, Dupont M, Yang W, Padjen AL (2002) Slow Na channel is upregulated in peripheral nerves of diabetic rats. Abstr Soc Neurosci 28

46. Shah BS, Gonzalez MI, Bramwell S, Pinnock RD, Lee K, Dixon AK (2001) Beta3, a novel auxiliary subunit for the voltage gated sodium channel is upregulated in sensory neurones following streptozocin induced diabetic neuropathy in rat. Neurosci Lett 309:1-4

47. Brown AA, Xu T, Arroyo EJ, et al. (2001) Molecular organization of the nodal region is not altered in spontaneously diabetic BB-Wistar rats. J Neurosci Res 65:139-149

48. Schneider U, Niedermeier W, Grafe P (1993) The paradox between resistance to hypoxia and liability to hypoxic damage in hyperglycemic peripheral nerves: evidence for glycolysis involvement. Diabetes 42:981-987

49. Bostock H, Baker M (1988) Evidence for two types of potassium channel in human motor axons in vivo. Brain Res 462:354-358

50. Bostock H, Burke D, Hales JP (1994) Differences in behaviour of sensory and motor axons following release of ischaemia. Brain 117:225-234

51. Ahlgren SC, Levine JD (1993) Mechanical hyperalgesia in streptozotocin-diabetic rats. Neurosci 52:1049-1055

52. Courteix C, Eschalier A, Lavarenne J (1993) Streptozocininduced diabetic rats: behavioural evidence for a model of chronic pain. Pain 53:81-88

53. Malmberg AB, Yaksh TL, Calcutt NA (1993) Anti-nociceptive effects of the GM1 ganglioside derivative AGF 44 on the formalin test in normal and streptozotocin-diabetic rats. Neurosci Lett 161:45-48 
54. Calcutt NA, Jorge MC, Yaksh TL, Chaplan SR (1996) Tactile allodynia and formalin hyperalgesia in streptozotocindiabetic rats: effects of insulin, aldose reductase inhibition and lidocaine. Pain 68:293-299

55. Suarez GA, Dyck PJ (1999) Quantitative sensory assessment. In: Dyck PJ, Thomas PK (eds) Diabetic neuropathy. WB Saunders, Philadelphia, pp 151-170

56. Claus D, Mustafa C, Vogel W, Herz M, Neundoerfer B (1993) Assessment of diabetic neuropathy: Definition of norm and discrimination of abnormal nerve function. Muscle Nerve 16:757-768

57. McCormick DA, Pape HC (1990) Noradrenergic and serotonergic modulation of a hyperpolarization-activated cation current in thalamic relay neurones. J Physiol (Lond) 431: 319-342
58. Ingram SL, Williams JT (1996) Modulation of the hyperpolarization-activated current (Ih) by cyclic nucleotides in guinea-pig primary afferent neurons. J Physiol 492:97106

59. Akasu T, Shoji S (1994) cAMP-dependent inward rectifier current in neurons of the rat suprachiasmatic nucleus. Pflugers Arch 429:117-125

60. Goraya TY, Wilkins P, Douglas JG, Zhou J, Bertimattera LN (1995) Signal-transduction alterations in peripheralnerves from streptozotocin-induced diabetic rats. Neurosci Res 41:518-525

61. Shindo H, Tawata M, Onaya T (1993) Reduction of cyclic AMP in the sciatic nerve of rats made diabetic with streptozotocin and the mechanism involved. $\mathrm{J}$ Endocrinol $136: 431-438$ 